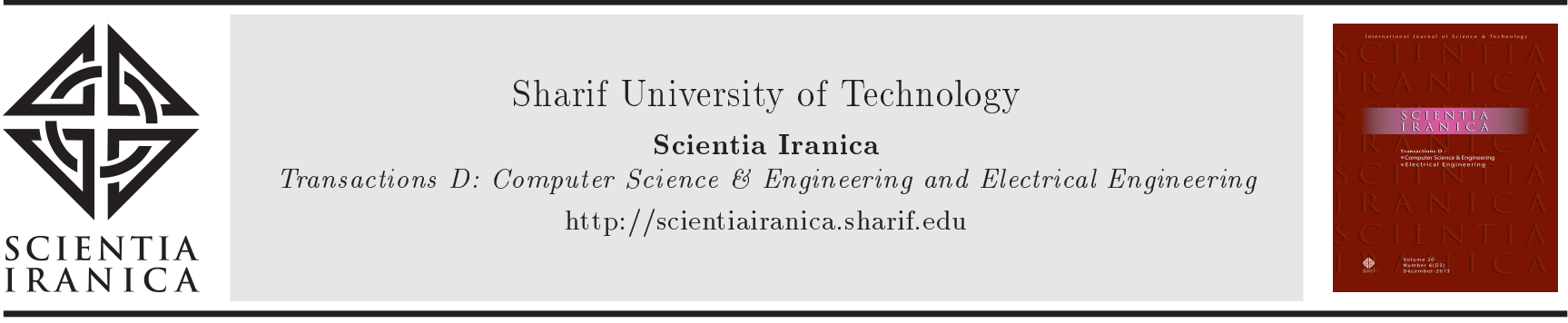

\title{
Performance and dynamic response enhancement of PMSG-based wind turbines employing boost converter-diode rectifier as the machine-side converter
}

\author{
A. Noori Khezrabad and M. Rahimi* \\ Department of Electrical and Computer Engineering, University of Kashan, Kashan, P.O. Box 87317-53153, Iran.
}

Received 7 September 2019; received in revised form 27 March 2020; accepted 1 June 2020

\author{
KEYWORDS \\ PMSG based WT; \\ Boost converter; \\ Torsional oscillation; \\ Auxiliary control \\ signals; \\ Dc-link voltage; \\ Low Voltage Ride \\ Through (LVRT); \\ Dc chopper.
}

\begin{abstract}
Wind Turbines (WTs) with Permanent Magnet Synchronous Generator (PMSG) are mostly integrated into power systems as popular energy conversion systems. From the Machine-Side Converter (MSC) structure point of view, there are two types of PMSG-WTs: PMSG-WT with Voltage Source Converter (VSC) as the MSC; PMSGWT with boost converter-diode rectifier as the MSC. The focus in this paper is on the control modification and dynamic and transient behavior improvement of PMSG-WTs with boost converter-diode rectifier. In this way, inner control loop of the boost converter current and outer control loop of generator speed are developed and extracted. Next, the boost converter control loop is modified by adding two auxiliary control signals, known as auxiliary damping signal and auxiliary compensation signal. The auxiliary damping signal modifies the boost converter current and provides a damping torque for inhibition of WT torsional oscillations. On the other hand, the auxiliary compensation signal, as the second auxiliary signal, limits the dc-link overvoltage during the voltage dip and amends the WT low-voltage ride through capability. By modifying the WT control through the second auxiliary signal, the size, cost, and rated energy of the required dc chopper resistance are reduced considerably.
\end{abstract}

(C) 2022 Sharif University of Technology. All rights reserved.

\section{Introduction}

Variable Speed Wind Turbines (VSWTs), as wellknown Wind Turbines (WTs) types, are mainly divided into two categories [1]: WTs with partially rated converters using Doubly Fed Induction Generator (DFIG) and WTs with fully rated converters. Depending on the generator type, there are three classes of WTs with fully rated converters in the wind power industry:

\footnotetext{
*. Corresponding author. Tel.: +983155913469 E-mail address: mrahimi@kashanu.ac.ir (M. Rahimi)
}

doi: $10.24200 /$ sci. 2020.54375 .3722
WTs with Permanent Magnet Synchronous Generator (PMSG) [2], WTs with wound rotor synchronous generator [3], and WTs with Squirrel Cage Induction Generator (SCIG) [4]. WTs with PMSG are largely used in wind power systems due to lower maintenance cost, simple structure, enhanced power factor, and better maximum power capability [5-9]. WTs with PMSG are linked to the electric network through back-to-back Voltage Source Converters (VSCs), called MachineSide Converter (MSC) and Grid-Side Converter (GSC). From the MSC structure point of view, there are two types of PMSG-WTs: PMSG-WT with VSC as the MSC [10] and PMSG-WT with boost converter-diode rectifier as the MSC [11]. Several research works have 
been done about the behavior analysis and control of PMSG-WTs employing VSC as the MSC. However, fewer publications have presented in-depth analytical studies regarding the PMSG-WTs by employing boost converter-diode rectifier as the MSC. Figure 1 depicts the system under study in which a PMSG-WT linked to the grid through boost converter-diode rectifier and VSC.

This paper is a continuation of the previous paper by Rahimi [11], where the pervious paper deals with the stability analysis in PMSG-WTs using boost converterdiode rectifier and examines the speed controller impact on the WT stability. However, the focus of this paper is on the control modification and dynamic and transient behavior improvement of PMSG-WTs with the boost converter-diode rectifier.

There are some papers [11-21] in the literature regarding different aspects of PMSG-WTs employing boost converter-diode rectifier. Rahimi [11] first dealt with the modeling and control of PMSG-WT and then, examined the effect of speed controller on the stability of WT by modal and small signal stability analyses. In [12-14], sensorless operation of small PMSG-WTs with a diode rectifier in the maximum power mode was discussed. In [12], the relation between the current and voltage on the dc side and in the maximum power mode was extracted and then, WT was controlled for operation in the maximum power mode. Yu and Liao [15] presented a maximum power mode algorithm, known as incremental conductance algorithm, for small PMSG WT supplying a dc load.

In [16], sliding mode control technique was employed and in $[17,18]$, the model predictive control approach was used for the control of PMSG-WT with boost converter-diode rectifier. In [19], an active power conditioner based on low power wind system was presented in which a boost converter fed from a PMSG was applied to battery charging. Studies [20,21] dealt with the operation of PMSG-WT with the boost converter-diode rectifier and energy storage system in stand-alone applications. Also, in [22], a sensorless control approach was presented for the improvement of maximum power mode operation in
PMSG-WT supplying a dc load via diode rectifier and boost converter.

In this paper, indeed, the boost converter control is modified in order to improve the damping of torsional oscillations under wind speed variations and limit the dc link overvoltage in voltage dip conditions.

In comparison with conventional power plants, the shaft stiffness coefficient in WTs is relatively low [23], which may result in torsional vibrations under wind speed variations or grid fault conditions. Torsional vibrations that appear on the shaft torsional torque may result in fatigue and stress in the drive train system. Usually, a two-mass model is used for describing the drive train system in WT dynamic studies.

Use of additional mechanical components mounted on the drive train is a method for damping improvement of torsional oscillations. However, it is expensive and requires additional space on the shaft. Using the ability of blade pitching and adjusting the WT mechanical torque by the pitch control system is an approach to suppressing the drive train oscillations in PMSG-based WTs. However, this method reduces the WT output and requires system pitch with faster dynamics. Several papers enhance the damping of torsional vibrations by modifying the MSC control system and via the generator speed feedback [24-29]. The mentioned approaches mainly function based on the generator speed feedback by employing the band pass or high-pass filters. However, the capability of these approaches is highly dependent on the band/high pass filter parameters and they may fail under uncertainty of the drive train system. There are also several papers that proposed other control approaches to damping of torsional oscillations in WTs. Liu et al. [30] proposed a damping and stiffness compensation control method to suppress the torsional vibration based on roots locus and bode graph. In [31], an adaptive fuzzy logic control-based structure was proposed for damping of torsional vibrations. In [32], a damping approach to damping of torsional oscillations was proposed based on feedback of the generator/turbine speed and shaft

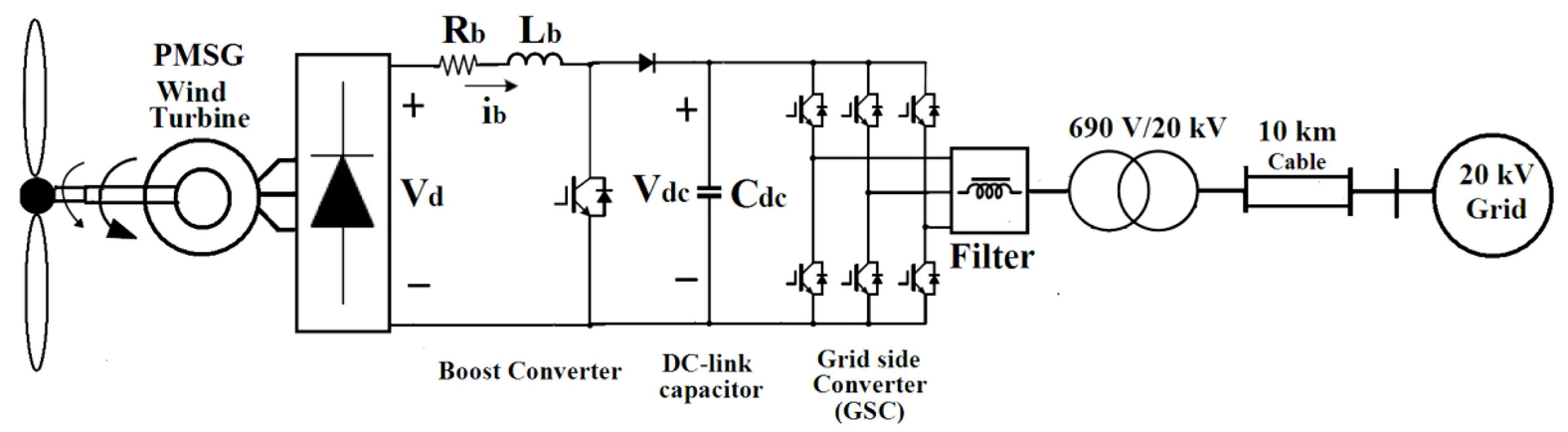

Figure 1. PMSG-WT linked to the grid via boost converter-diode rectifier and GSC. 
twist angle and employing band pass and notch filters. In [33], damping of torsional oscillations in WTs was investigated using the $H_{\infty}$ controller.

Further, there are some improved control approaches without band/high pass filters that have been proposed for PMSG WTs employing VSC as the MSC [34-36]. However, there are fewer analytical works regarding the WT control modification for improvement of torsional oscillations damping and limiting the dc link overvoltage under transient and dynamic conditions in PMSG WTs assisted with the diode rectifier-boost converter.

The main outlines of this section are as follows. This research first presents the control structure of PMSG-WTs assisted with the boost converter-diode rectifier, in which the boost converter is used for controlling the generator speed in the maximum operation mode and the GSC is used for setting the dc-link to a constant value. In this way, the relation between the mean values of the boost converter current and q-component stator current is extracted after which the PMSG torque is expressed in terms of the boostconverter current. Then, control loops of the generator speed and boost converter current are extracted. Next, as the main contribution, the boost converter control loop is modified by adding two auxiliary control signals, known as auxiliary damping signal and auxiliary compensation signal. The auxiliary damping signal modifies the boost converter current and the PMSG torque by the feedback of the generator and turbine speeds. In addition, it provides a damping torque for inhibition of WT torsional oscillations. On the other hand, the second auxiliary signal, known as the auxiliary compensation signal, limits the dc link overvoltage through the feedback of the dc-link voltage during the voltage dips and enhances the WT LVRT ability. Upon modifying the WT control through second auxiliary signal, the size, cost, and rated energy of the required dc chopper decrease considerably. At the end, the WT performance with the modified control structure is studied and simulation results are presented.

\section{PMSG modeling}

Figure 1 shows a grid-connected WT in which a surfacemounted PMSG is connected to the grid via diode rectifier-boost converter and GSC.

For a surface-mounted PMSG, the stator voltages/fluxes in the rotating dq reference frame with the angular speed of $\omega_{r}$, are given as follows [10]:

$$
\begin{aligned}
& v_{s d q}=R_{s} i_{s d q}+j \omega_{r} \psi_{s d q}+\frac{d \psi_{s d q}}{d t}, \\
& \psi_{s d}=L_{s} i_{s d}+\psi_{p m}, \quad \psi_{s q}=L_{s} i_{q} .
\end{aligned}
$$

where $\psi, v$, and $i$ denote the flux, voltage and current, and subscript $s$ stands for the stator variables. $L_{s}$ and $R_{s}$ are the synchronous inductance and stator resistance, respectively. $\psi_{p m}$ is the stator flux linkage due to rotor permanent magnet and $\omega_{r}$ is the rotor electrical speed. In steady state conditions, $\omega_{r}$ is equal to the stator frequency, $\omega_{s}$. Further, the generator torque in a surface-mounted PMSG can be given as follows:

$$
T_{e}=\frac{3}{2} n_{p}\left(\psi_{p m} i_{s q}\right)
$$

where $n_{p}$ is the number of generator pole pairs. By setting the stator flux derivative to zero in Eq. (1) and using Eq. (2), the PMSG steady-state model is achieved, as given in Eq. (4):

$$
v_{s d q}=R_{s} i_{s d q}+j X_{s} i_{s d q}+j \omega_{r} \psi_{p m}
$$

where $j \omega_{r} \psi_{p m}$ in Eq. (4) is internal back-emf voltage induced in the stator.

From Eq. (4), the equivalent circuit of each PMSG phase in steady state conditions is obtained, as depicted in Figure 2, where $X_{s}$ and $R_{s}$ are the stator synchronous reactance and resistance, respectively.

The direction of the stator current in Figure 2 is considered in the stator winding. $E_{g}$ in Figure 2 is the back-emf voltage induced in the stator and is given by $E_{g}=j \omega_{r} \psi_{p m}$.

If the inductor $L_{b}$ related to the boost converter is selected to be sufficiently large, the boost converter works in the Continuous Conduction Mode (CCM). The boost converter current $i_{b}$, see Figure 1 , in the CCM is continuously modeled as a dc current source at the output of the diode rectifier, as depicted in Figure 3.

In Figure $3, E_{a g}, E_{b g}$, and $E_{c g}$ are the three phase back-emf voltages, $V_{d}$ is the rectifier output

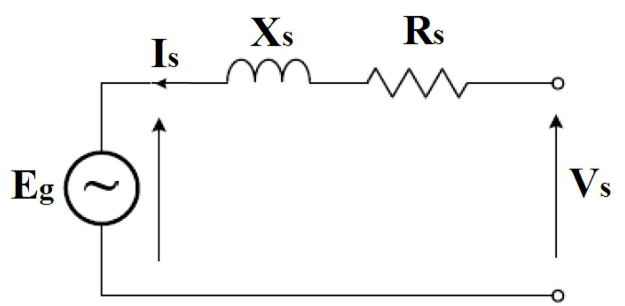

Figure 2. Equivalent circuit for one phase of PMSG.

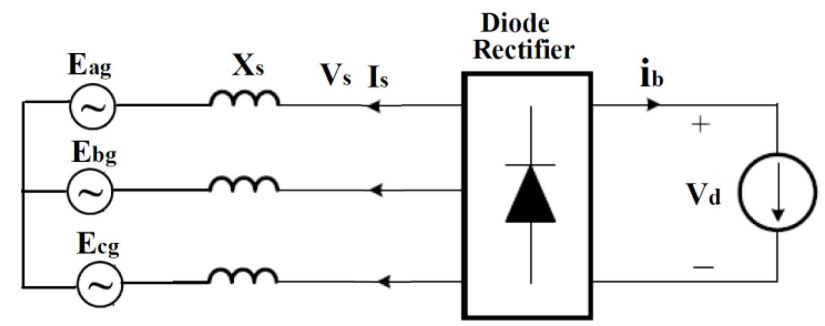

Figure 3. Equivalent circuit of the PMSG, diode rectifier, and boost converter at the CCM in steady-state conditions. 
voltage, and $i_{b}$ is the boost converter current. The stator resistance is small compared to $X_{s}$ and thus, in Figure $3, R_{s}$ is neglected in order to simplify the analysis. According to this study [37], the rectifier average output voltage can be given as follows:

$$
v_{d}=\frac{3 \sqrt{3}}{\pi}\left|E_{g}\right|-\frac{3}{\pi} X_{s} i_{b}
$$

where $\left|E_{g}\right|=\omega_{r} \psi_{p m}$ is the stator back-emf voltage. In Eq. (5), the second term, $(3 / \pi) X_{s} i_{b}$, is the average output voltage drop of the rectifier caused due to the presence of synchronous reactance $X_{s}$. It is noted that the current commutation in the diode rectifier, due to reactance $X_{s}$, is not instantaneous, resulting in rectifier output voltage drop.

\subsection{PMSG torque representation as a function of boost converter current}

According to Eq. (4) and Figure 2 and by neglecting the stator resistance, the PMSG output active power can be given by:

$$
P_{s}=-\frac{3}{2} \omega_{r} \psi_{p m} i_{s q}
$$

Due to the nonlinear nature of the diode rectifier, higher harmonics appear on the three-phase stator currents. In the synchronous reference frame, the stator currents with the fundamental frequency appear as dc components and other harmonics as ac ripples with frequency of $6 \omega_{0}$ ( $\omega_{0}$ is the fundamental frequency). The active power related to higher current harmonics is negligible and thus, power transfer in Eq. (6) is done by the fundamental component of the stator current and consequently, by the average component of the $q$-axis stator current, $\bar{i}_{s q}$. Hence, the average output active power of the PMSG is given by:

$$
\bar{P}_{s}=-\frac{3}{2}\left|E_{g}\right| \bar{i}_{s q}=-\frac{3}{2} \omega_{r} \psi_{p m} \bar{i}_{s q}
$$

where the superscript - in Eq. (7) stands for average value. According to Figure 3, the diode rectifier output power is given as $P_{d}=v_{d} i_{b}$. Hence, by neglecting the rectifier losses, the PMSG average output power and the rectifier output power are identical and thus, according to Eqs. (5) and (7), it is concluded that:

$$
-\frac{3}{2}\left|E_{g}\right| \bar{i}_{s q}=\left(\frac{3 \sqrt{3}}{\pi}\left|E_{g}\right|-\frac{3}{\pi} X_{s} i_{b}\right) i_{b} .
$$

From Eq. (8), the relationship between the boost converter current $i_{b}$ and $\bar{i}_{s q}$ is obtained. Using Eq. (8), $i_{b}$ can be given as follows:

$$
\begin{aligned}
i_{b} & =\frac{\frac{3 \sqrt{3}}{\pi}\left|E_{g}\right| \pm \sqrt{\left(27 / \pi^{2}\right)\left|E_{g}\right|^{2}-(18 / \pi)\left|E_{g}\right| X_{s} \bar{i}_{s q}}}{(6 / \pi) X_{s}} \\
& =\frac{\frac{3 \sqrt{3}}{\pi}\left|E_{g}\right| \pm \sqrt{\left(27 / \pi^{2}\right)\left|E_{g}\right|^{2}-(12 / \pi) X_{s} \bar{P}_{s}}}{(6 / \pi) X_{s}} .
\end{aligned}
$$

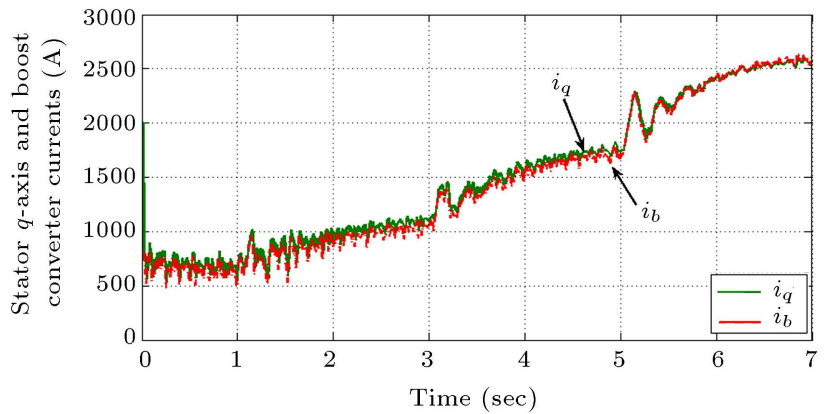

Figure 4. Average values of the boost converter current and $q$-component stator current at different wind speeds for the study system.

From Eq. (9), there is a real solution for $i_{b}$ if the following constraint is satisfied:

$$
\left|E_{g}\right| \geq \frac{2}{3} \sqrt{\pi X_{s} \bar{P}_{s}}
$$

Figure 4 shows the average values of the $q$-component stator current $\bar{i}_{s q}$ and boost converter current $i_{b}$ in response to the wind speed change from 6 to $12 \mathrm{~m} / \mathrm{s}$ for the study system with parameters of the Appendix. According to Figure 4, at different wind speeds, the values of $\left|\bar{i}_{s q}\right|$ and $i_{b}$ are relatively identical and thus, for a wide operating range, we can write $\left|\bar{i}_{s q}\right|=i_{b}$. Hence, according to Eq. (3), the PMSG torque as a function of $i_{b}$ may be approximated by:

$$
T_{e}=-\frac{3}{2} n_{p}\left(\psi_{p m} i_{b}\right)
$$

\section{Average dynamic model and control of the combined system}

For the controller design and dynamic performance analysis of the PMSG-WT, it is required to find the PMSG model from the rectifier output point of view. Considering Figure 1 and according to [38], the PMSG and diode-rectifier can be modeled with an appropriate equivalent dc circuit on the dc-side, as depicted in Figure 5, in which $u_{d c}=(3 \sqrt{3} / \pi)\left|E_{g}\right|=$ $(3 \sqrt{3} / \pi) \omega_{r} \psi_{p m}, R=2 R_{s}+(3 / \pi) X_{s}$, and $L=2 L_{s}$. Also, $R_{b}$ and $L_{b}$ are the resistance and inductance of the boost converter inductor, and $v_{d c}$ is the voltage of the dc-link capacitor. According to Figure 4, the rectifier output current can be controlled by changing the duty cycle, $d$, of the switch SW. Assuming the CCM

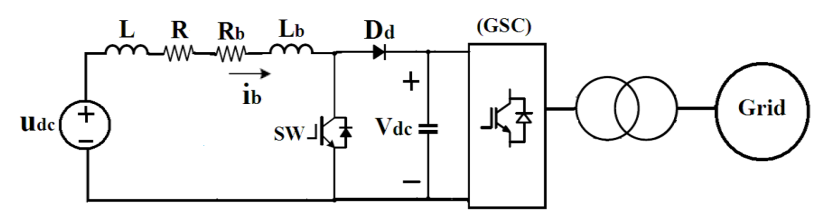

Figure 5. Simplified model of the PMSG-diode rectifier connected to the boost converter. 


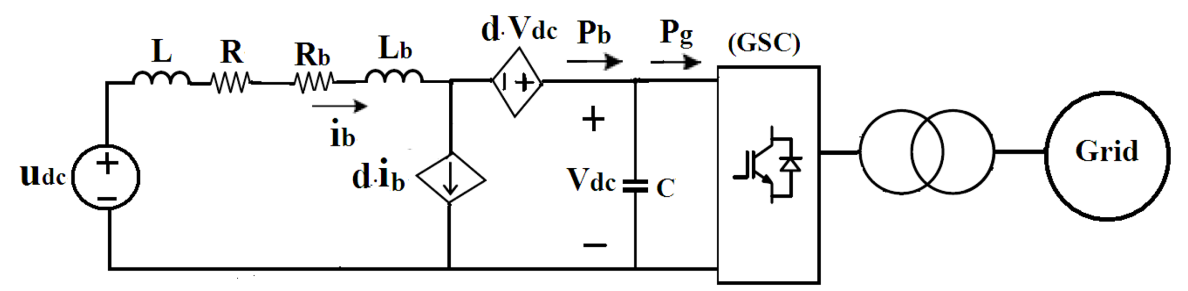

Figure 6. Boost converter average model in CCM mode.

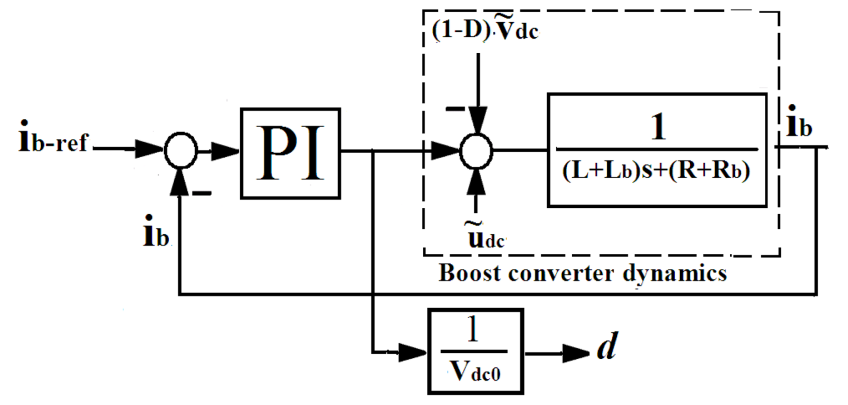

Figure 7. Boost converter current control loop.

operation for the boost converter, there are two states: the first state corresponding to when the SW is on and the second one associated to when the switch SW is off. The average model of the PMSG-rectifier-boost converter can be extracted, as depicted in Figure 6 .

Considering Figure 6, the average representation of the boost converter dynamics over a switching period can be given as:

$$
u_{d c}=\left(R+R_{b}\right) i_{b}+\left(L+L_{b}\right) \frac{d i_{b}}{d t}+v_{d c}(1-d),
$$

where $d$ stands for the duty cycle of the switch, SW. It is assumed that $d=D+\tilde{d}, i_{d c}=I_{d c}+\tilde{i}_{d c}, u_{d}=U_{d}+\tilde{u}_{d}$, and $v_{d c}=V_{d c}+\tilde{v}_{d c}$, where $\sim$ denotes the small signal variation and the capital letter represents the variables at the operating point. Considering Eq. (12), the small signal from the boost converter dynamics is obtained as:

$$
\begin{aligned}
& \left(L+L_{b}\right) \frac{d \tilde{i}_{b}}{d t}+\left(R+R_{b}\right) \tilde{i}_{b}=\tilde{d} V_{d c 0}-\tilde{v}_{d c}(1-D) \\
& +\tilde{u}_{d c} .
\end{aligned}
$$

According to Eq. (13) and by employing the PI controller, $P I_{I_{b}}(s)=k_{p}+k_{i} / s$, the following boost converter current control loop, depicted in Figure 7 , is achieved, where $d$ as the control signal adjusts $i_{b}$ to the reference value.

In Figure 7, by using the pole-zero cancellation method, it is concluded that $k_{p} / k_{i}=$ $\left(R+R_{b}\right) /\left(L+L_{b}\right)$. Hence, by selecting $k_{p}=\omega_{i}(L+$ $\left.L_{b}\right)$, the transfer function from $i_{b-r e f}$ to $i_{b}$ will be:

$$
\frac{i_{b}(s)}{i_{b-r e f}(s)}=\frac{\omega_{i}}{s+\omega_{i}},
$$

where $\omega_{i}$ is the closed-loop bandwidth of the boost converter current control loop and $\omega_{i}=k_{p} /\left(L+L_{b}\right)$. Considering Eq. (11), there is a direct relation between the generator torque $T_{e}$ and boost converter current $i_{b}$. Hence, the reference current $i_{b-r e f}$ in Figure 7 is assigned by the outer speed controller.

\subsection{Speed control loop of PMSG}

In this section, the PMSG speed is controlled in the maximum power mode via the boost converter current control. The two-mass representation is usually used for modeling the WT drive train and is given by:

$$
\begin{aligned}
& 2 H_{g} \frac{d \omega_{r-p u}}{d t}=T_{e-p u}+T_{s h-p u}, \\
& \frac{d \theta_{s h}}{d t}=\omega_{b}\left(\omega_{t-p u}-\omega_{r-p u}\right), \\
& 2 H_{t} \frac{d \omega_{t-p u}}{d t}=T_{t-p u}-T_{s h-p u}, \\
& T_{s h-p u}=k_{s} \theta_{s h}+D_{t g}\left(\omega_{t-p u}-\omega_{r-p u}\right) .
\end{aligned}
$$

In the two-mass model, a spring and a damper similar to those in the flexible shaft model are considered between the turbine low speed mass and generator high speed mass. The subscript $p u$ in Eqs. (15)-(18) and Figure 8 stands for per unit (pu), and $\omega_{t-p u}$ and $\omega_{r-p u}$ are the speeds of the turbine and generator (in pu), $\theta_{s h}$ is the angle of the shaft twist (in rad), $H_{g}$ and $H_{t}$ are the generator and turbine inertia constants (in sec), respectively, $k_{s}$ is the shaft stiffness (in pu/elec. $\mathrm{rad}), D_{t g}$ is the damping coefficient of the shaft (in $\mathrm{pu}), T_{e-p u}$ and $T_{t-p u}$ are the generator and turbine torques, respectively, (in pu), and $T_{s h-p u}$ is the shaft torque, (in pu). Figure 8 shows the speed control loop of the PMSG-WT.

The term $\omega_{i} /\left(s+\omega_{i}\right)$ in Figure 8 corresponds to the boost converter current control loop and thus, the boost converter reference current is obtained from the outer speed controller.

\section{WT performance improvement through control system modification}

In this section, the performance of the WT is enhanced by modifying the WT control system. The modified 


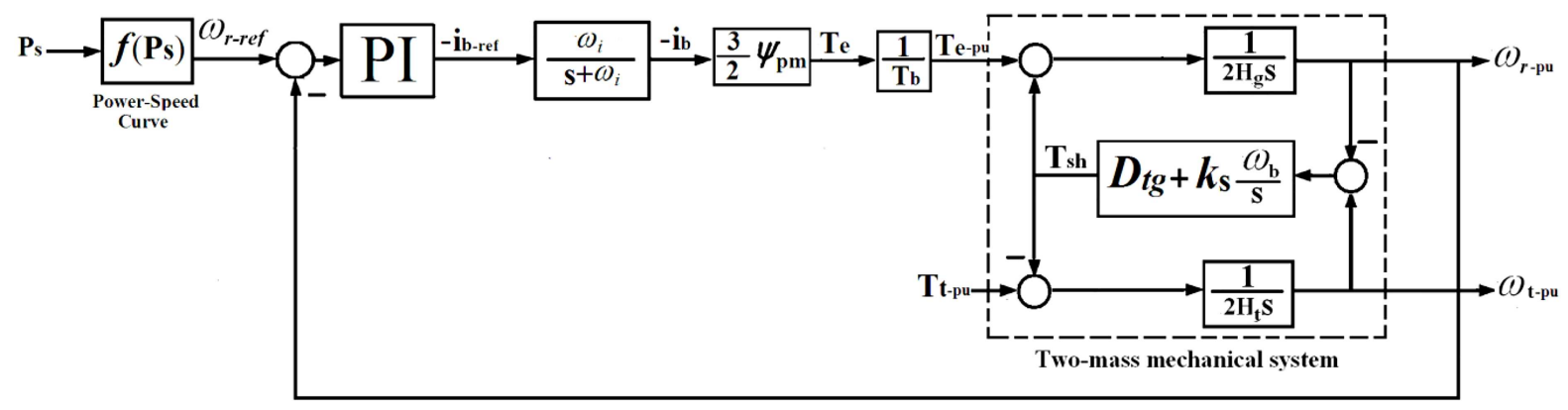

Figure 8. Speed control loop of the PMSG-WT.

control system, in turn, enhances the damping of torsional oscillations that appeared in the shaft torsional torque, and it limits the dc-link voltage variations under transient conditions. The above-mentioned improvements are realized by adding auxiliary control signals and updating the boost converter current reference, as are shown in Subsections 4.1 and 4.2.

\subsection{Damping of shaft torsional torque oscillations}

Considering Eqs. (15)-(18), the shaft torsional torque dynamics, in terms of $T_{e-p u}$ and $T_{t-p u}$, may be given as follows:

$$
\begin{aligned}
& \frac{d^{2} \tilde{T}_{s h-p u}}{d t^{2}}+\frac{D_{t g}}{2 H_{e q}} \frac{d \tilde{T}_{s h-p u}}{d t}+\frac{k_{s} \omega_{b}}{2 H_{e q}} \tilde{T}_{s h-p u} \\
& \quad=\frac{k_{s} \omega_{b}}{2}\left(\frac{\tilde{T}_{t}}{H_{t}}-\frac{\tilde{T}_{e}}{H_{g}}\right)+\frac{D_{t g}}{2} \frac{d}{d t}\left(\frac{\tilde{T}_{t}}{H_{t}}-\frac{\tilde{T}_{e}}{H_{g}}\right)
\end{aligned}
$$

where $H_{e q}=\frac{H_{g} H_{t}}{H_{g}+H_{t}}$ and symbol $\sim$ denotes the small variation around the operating point. According to Eq. (19), the shaft torsional torque natural frequency, $\omega_{n}$, and damping ratio, $\xi$, are obtained as follows: $\omega_{n}=$ $\sqrt{\frac{k_{s} \omega_{b}}{2 H_{e q}}}$ and $\xi=\frac{D_{t g}}{2} \sqrt{\frac{1}{k_{s} \omega_{b}} \frac{1}{2 H_{e q}}}$. In WTs, $D_{t g}$ as the shaft damping coefficient is relatively small resulting in the low value of damping ratio $\xi$. Considering Eq. (19), if the PMSG torque $T_{e}$ and the boost converter current $i_{b}$ contain a component proportional to $d \tilde{T}_{s h-p u} / d t$, the damping of shaft torsional oscillations can be actively increased. According to Eqs. (16) and (18), $d \tilde{T}_{s h-p u} / d t$ is given as follows:

$$
\begin{aligned}
\frac{d \tilde{T}_{s h-p u}}{d t}= & k_{s} \omega_{b}\left(\tilde{\omega}_{t-p u}-\tilde{\omega}_{r-p u}\right) \\
& +D_{t g} \frac{d}{d t}\left(\tilde{\omega}_{t-p u}-\tilde{\omega}_{r-p u}\right) .
\end{aligned}
$$

By neglecting $D_{t g}$, Eq. (20) can be approximated by:

$$
\frac{d \tilde{T}_{s h-p u}}{d t}=k_{s} \omega_{b}\left(\tilde{\omega}_{t-p u}-\tilde{\omega}_{r-p u}\right) .
$$

Hence, from Eq. (21), for damping enhancement of shaft torsional oscillations, it is required that the electromagnetic torque $T_{e}$ and the boost converter current $i_{b}$ have a component proportional to $\left(\omega_{t}-\omega_{r}\right)$. To this end, the reference of the boost converter current is modified by adding an auxiliary damping signal $i_{b 1-a u x}$, as shown in Figure 9. Figure 9(a) shows the modified boost converter current control loop including the auxiliary damping signal $i_{b 1-a u x}$. Also, Figure 9(b) shows the closed-loop generator speed control system with the auxiliary damping signal. Hence, when torsional oscillations in the generator speed appear, the auxiliary signal $i_{b 1-a u x}$, with the same frequency of torsional oscillations, is generated and thus, a damping torque reducing the shaft torque oscillations is obtained.

\subsection{Restriction of dc-link voltage variations in transient states}

In PMSG-based WTs, during the grid fault and voltage dip, the output power injected to the grid drops down and thus, the dc-link voltage may go over the allowable range and damage the dc-link capacitor. To limit the dc-link voltage variation under grid fault conditions, we can modify the boost converter current $i_{b-r e f}$ by adding an auxiliary signal $i_{b 2-a u x}$, as shown in Figure 10. Figure 10(a) depicts the modified boost converter current control loop comprising the auxiliary compensation signal $i_{b 2-a u x}$ by alleviating the dc-link voltage overvoltage below $1.1 V_{d c-r e f}$ during the grid voltage dips. Also, Figure 10(b) shows the closed-loop generator speed control system with the second auxiliary compensation signal $i_{b 2-a u x}$. In Figure 10, the compensation gain $K_{2-a u x}$ converts the dc-link voltage variations into an auxiliary compensation signal, thus reducing the dc-link voltage change under grid voltage dip.

\section{Simulation studies}

In this section, the simulation results for the study system are presented. The study system is given in accordance with Figure 1 in which a grid-connected 


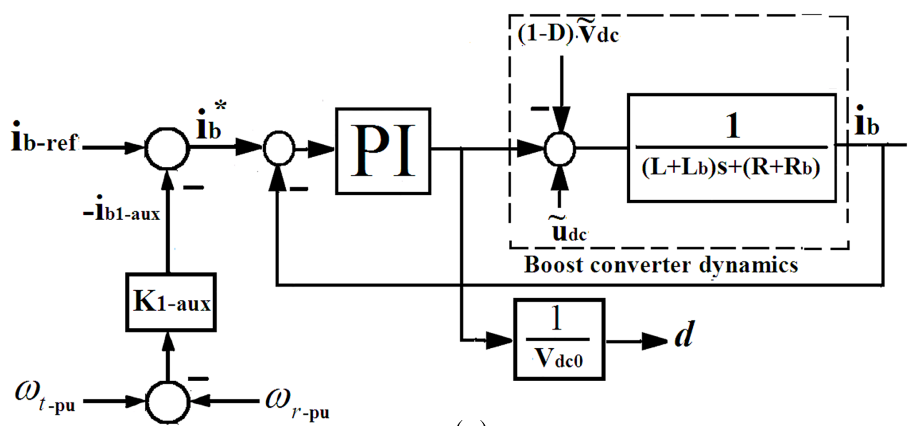

(a)

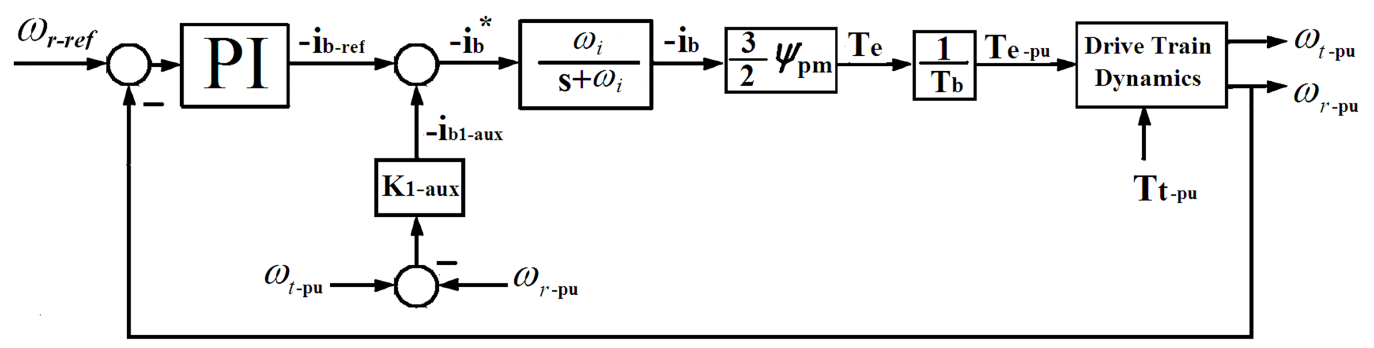

(b)

Figure 9. Modified PMSG control system for damping of torsional oscillations: (a) Boost converter inner current control loop and (b) generator speed outer control loop.
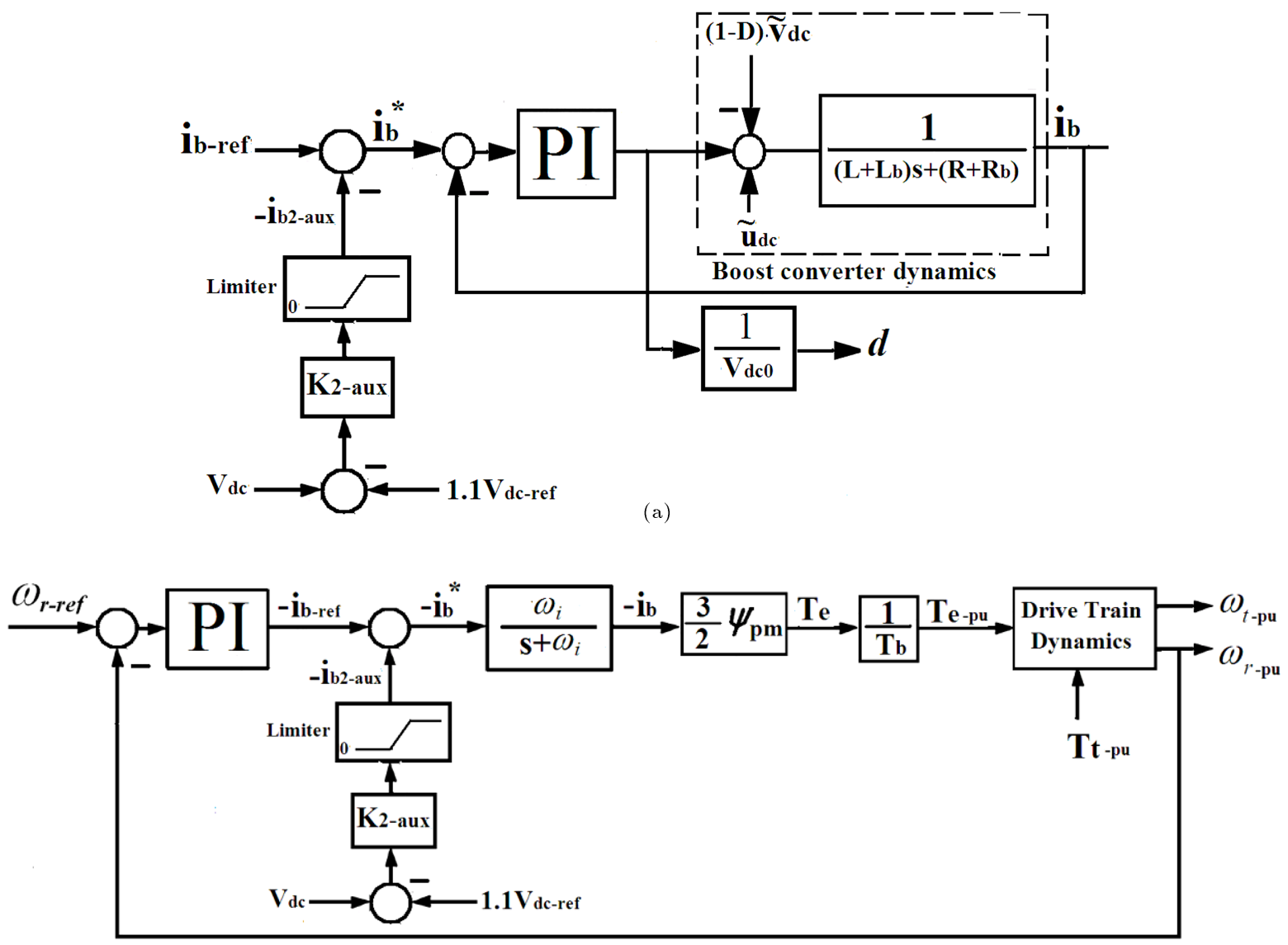

(b)

Figure 10. Modified PMSG control system for limiting the dc-link voltage variations: (a) Boost converter inner current control loop and (b) generator speed outer control loop. 
PMSG WT is connected to a $20 \mathrm{kV}$ grid (with shortcircuit power of $20 \mathrm{MVA}$ ) via diode rectifier-boost converter, GSC, related $690 \mathrm{~V} / 20 \mathrm{kV}$ transformer, and $1 \mathrm{~km}$ transmission line. The system parameters under study are given in Table A.1 in the Appendix. Simulation results are done in MATLAB-Simulink environment with the sampling period of $10 \mu$ sec (sampling frequency of $100 \mathrm{kHz}$ ).

Figure 11 depicts $d$ and $q$ components of the stator current and boost converter current for the wind speeds of 10 and $12 \mathrm{~m} / \mathrm{sec}$. As explained before, due to the presence of the full bridge rectifier operating in the CCM mode, the three-phase stator currents comprise the fundamental frequency and harmonic components. Hence, as depicted in Figure 11(a) and (b), $i_{s d}$ and $i_{s q}$ are not constant and contain ac harmonic ripples. The mean value of $i_{s q}$ is responsible for energy conversion and generator speed control. As shown in Figure 11(b), the average values of $i_{s q}$ for wind speeds of 10 and $12 \mathrm{~m} / \mathrm{sec}$ are $2010 \mathrm{~A}$ and $2550 \mathrm{~A}$, respectively. Also, according to Figure 11(c), the average values of the boost converter current $i_{b}$ at wind speeds of 10 and 12 $\mathrm{m} / \mathrm{sec}$ are $2000 \mathrm{~A}$ and $2550 \mathrm{~A}$, which are approximately identical to the average values of $i_{s q}$.

Figure 12 shows time responses of the GSC three phase AC currents and GSC active and reactive powers injected to the grid at a wind speed of $12 \mathrm{~m} / \mathrm{sec}$. It is clear that at $V_{w}=12 \mathrm{~m} / \mathrm{sec}$, the amplitude of the GSC currents is $0.98 \mathrm{pu}$ and the active power is $P_{g}=0.98$ pu. Furthermore, since the GSC is controlled at unity power factor, the injected reactive power to the grid is equal to zero $Q_{g}=0$. Also, Figure 13 shows GSC phase $a$ current and corresponding FFT analysis. According to FFT analysis of Figure 13, the THD of the GSC current is $1.64 \%$, and the magnitude of the highest harmonic relative to fundamental component is $0.8 \%$. Table 1 shows current distortion limits for systems rated at $120 \mathrm{~V}$ to $69 \mathrm{kV}$ according to IEEE standard-519. In the study system, the grid shortcircuit power at the connection point of the WT to the grid is greater than $100 \mathrm{MVA}$. Since the rated power the WT is $2 \mathrm{MW}$, the short-circuit ratio of the grid at the connection point of the WT is more than 50 . According to Table 1, the allowable value of the THD current at $I_{s c} / I_{L}>50$ is $12 \%$ and thus, the WT THD current meets the IEEE standard-519.

Figure 14 shows responses of the generator speed and shaft torsional torque for the step change of the wind speed from $10 \mathrm{~m} / \mathrm{sec}$ to $12 \mathrm{~m} / \mathrm{sec}$. In Figure 14 , the damping action of the control system with the proposed auxiliary damping signal is compared with the capability of the one without the auxiliary damping signal. According to Figure 14, after the wind speed step change, torsional oscillations appear in $T_{s h}$ and $\omega_{r}$, where in the case of the auxiliary damping signal, these oscillations are damped faster.

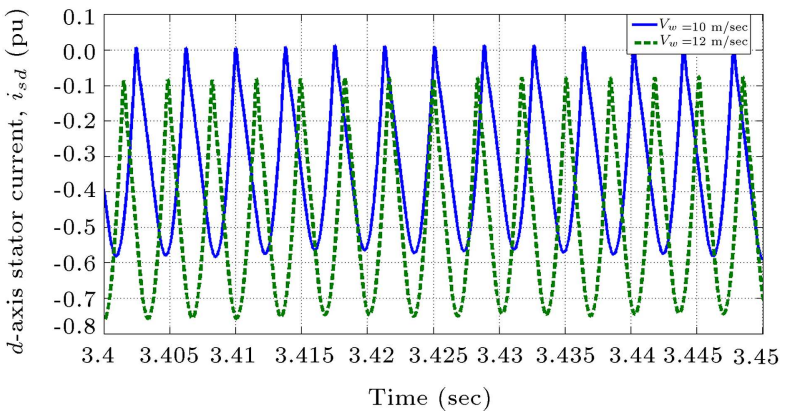

(a)

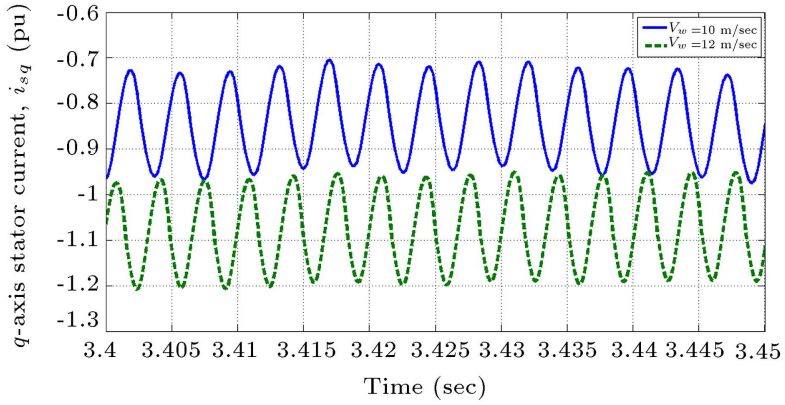

(b)

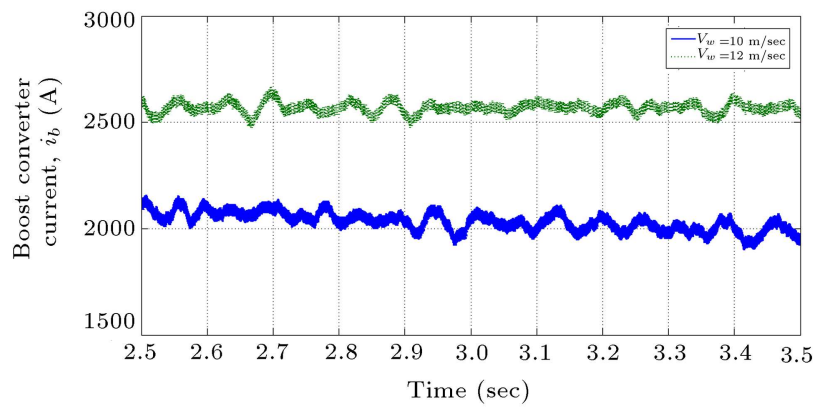

(c)

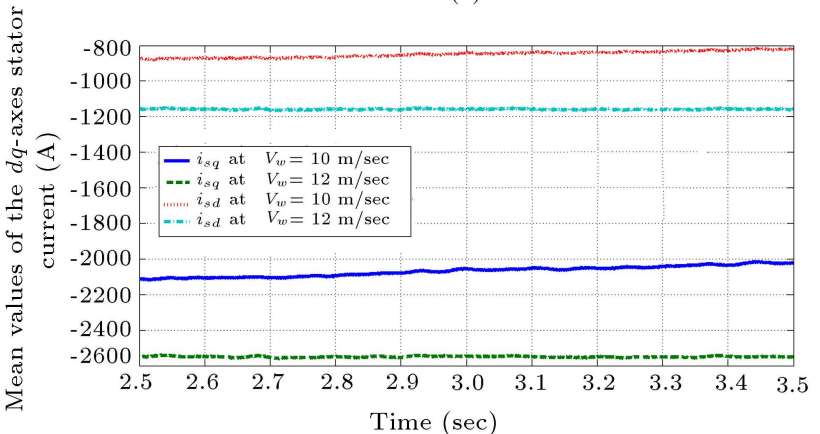

(d)

Figure 11. System time responses for the wind speeds of 10 and $12 \mathrm{~m} / \mathrm{sec}$ : (a) $d$-component stator current, (b) $q$-component stator current, (c) boost converter current, and (d) mean values of $d q$ axes stator current.

In the following (in Figure 15), the performance of the proposed damping approach in Figure 9 is compared with that of the damping approach based on the generator speed feedback. Considering Figure 15, it is clear that the proposed active damping approach is more effective than the approach based on the generator speed feedback in damping torsional oscillations. 
Table 1. Current distortion limits for systems rated at $120 \mathrm{~V}$ to $69 \mathrm{kV}$ in line with IEEE standard-519.

\begin{tabular}{|c|c|c|c|c|c|c|}
\hline \multicolumn{7}{|c|}{ Maximum harmonic current distortion in percentage of $I_{L}$} \\
\hline \multicolumn{7}{|c|}{ Individual harmonic order } \\
\hline \multicolumn{7}{|c|}{$\begin{array}{c}I_{L}: \text { Maximum demand load current (fundamental frequency component) at the PCC under } \\
\text { normal operating conditions }\end{array}$} \\
\hline$I_{s c} / I_{L}$ & $3 \leq h<11$ & $11 \leq h<17$ & $17 \leq h<23$ & $23 \leq h<35$ & $35 \leq h \leq 50$ & THD \\
\hline$<20$ & 4 & 2 & 1.5 & 0.6 & 0.3 & 5 \\
\hline $20<50$ & 7 & 3.5 & 2.5 & 1 & 0.5 & 8 \\
\hline $50<100$ & 10 & 4.5 & 4 & 1.5 & 0.7 & 12 \\
\hline $100<1000$ & 12 & 5.5 & 5 & 2 & 1 & 15 \\
\hline$>1000$ & 15 & 7 & 6 & 2.5 & 1.4 & 20 \\
\hline
\end{tabular}

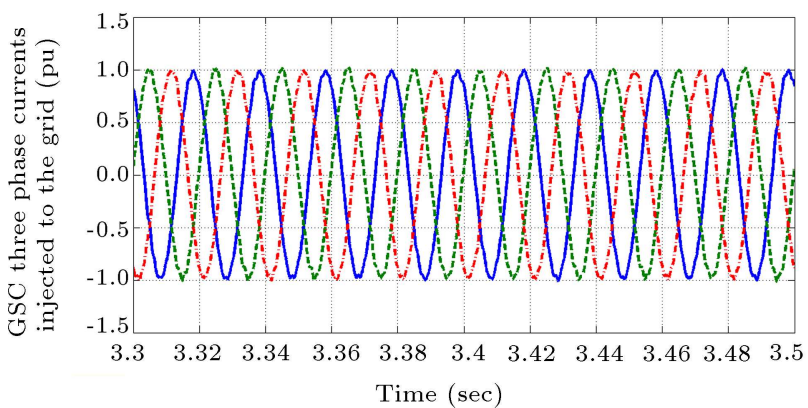

(a)

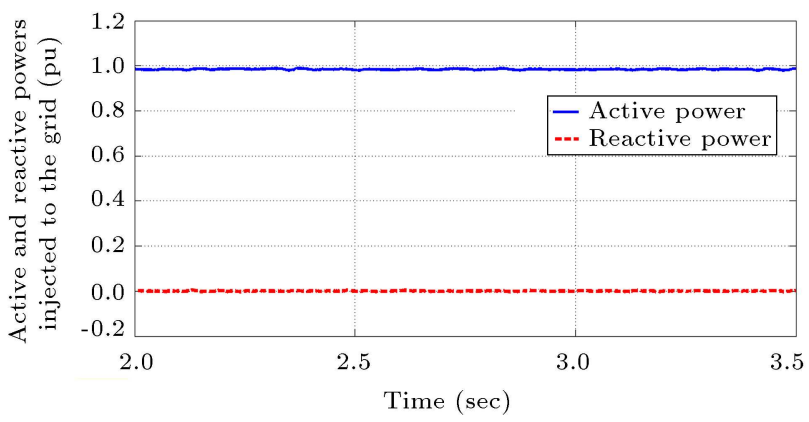

(b)

Figure 12. GSC time responses at a wind speed of 12 $\mathrm{m} / \mathrm{sec}$ : (a) GSC three phase AC currents and (b) GSC active and reactive power injected to the grid.

Figure 16 shows the time response of the dc-link voltage once a $70 \%$ voltage dip with a duration of $100 \mathrm{msec}$ is imposed on the grid. In Figure 16, the effectiveness of the control system with the proposed auxiliary compensation signal (proposed in Subsection 4.2 ) is compared with the capability of the one without the auxiliary compensation signal. It is noted that the dc-link voltage under normal steady state conditions is 1100 V. According to Figure 16, once the voltage dip is imposed on the grid, the output active power injected to the grid by the grid-side converter drops down, resulting in overvoltage in the dc-link voltage. According to Figure 16, in the case without the auxiliary compensation signal, the dc-link voltage reaches the
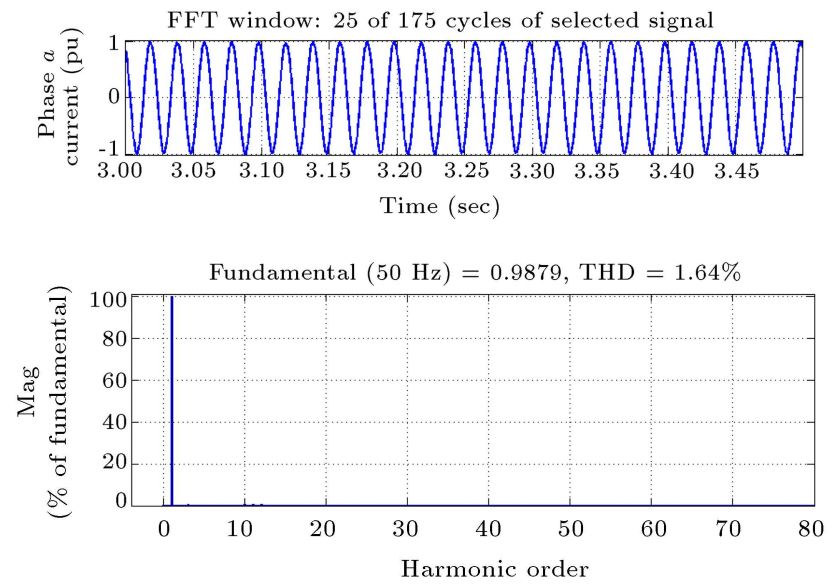

Figure 13. GSC phase $a$ current and Fast Fourier Transform (FFT) analysis with Total Harmonic Distortion (THD) of $1.64 \%$.

large value of $2200 \mathrm{~V}$ damaging the dc-link capacitor. In the case with the auxiliary compensation signal, the power imported to the dc-link from the stator is reduced and thus, the peak of the dc-link voltage is limited to $1350 \mathrm{~V}$ following the occurrence of the voltage dip. Hence, by using the proposed method in Figure 10, the change in the dc-link voltage due to voltage dip decreases considerably. This, in turn, enhances the LVRT behavior of the turbine generator.

Figure 17 shows the time responses of the system under both wind speed variations and grid volatge dip, with and without the proposed compensation approaches. In the case of the proposed compensation approaches, both auxiliary signals of Figures 9 and 10 are applied to the boost converter control in order to damp torsional oscollations and limit the dc-link over voltage. According to Figure 17, it is clear that through the proposed compensation approaches, torsional oscillations are well damped and dc-link over voltage is limited below the threshold value.

Figure 18 shows the dc link voltage under $70 \%$ single-phase volatge dip. According to Figure 18, the 


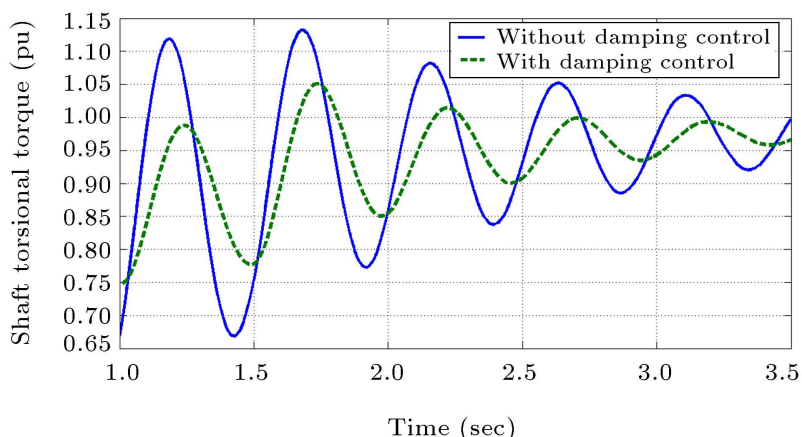

(a)

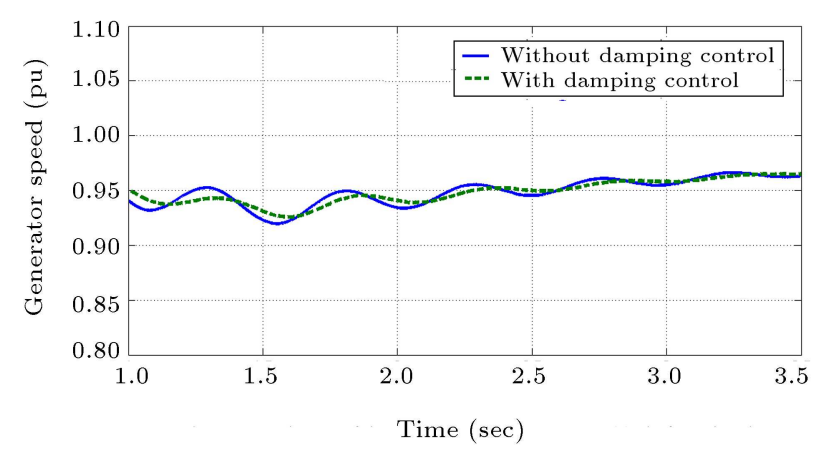

(b)

Figure 14. System responses due to step change of the wind speed from 10 to 12: (a) Shaft torsional torque and (b) generator speed.

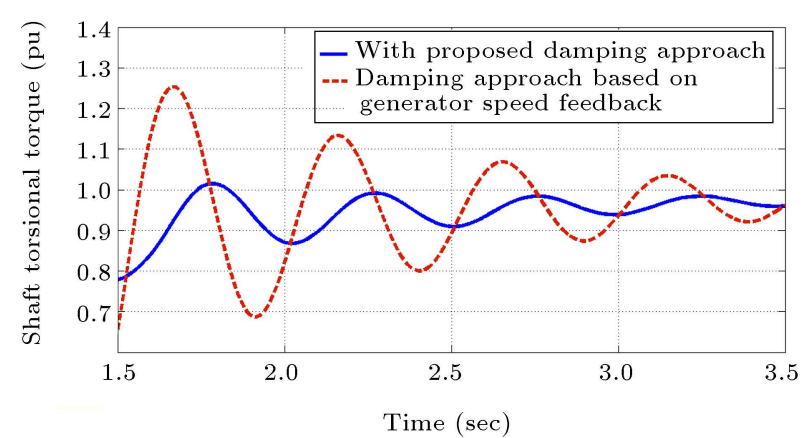

(a)

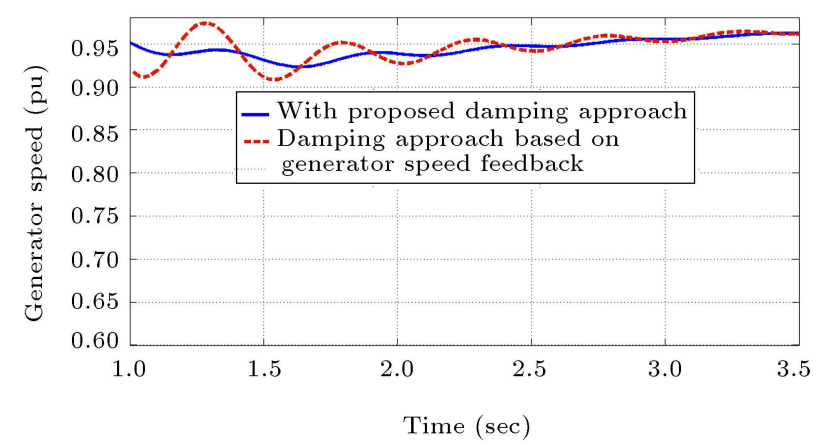

(b)

Figure 15. Time responses of shaft torsional torque and generator speed to a step change of the wind speed for two different damping approaches (i.e., proposed damping approach and damping approach based on the generator speed feedback).

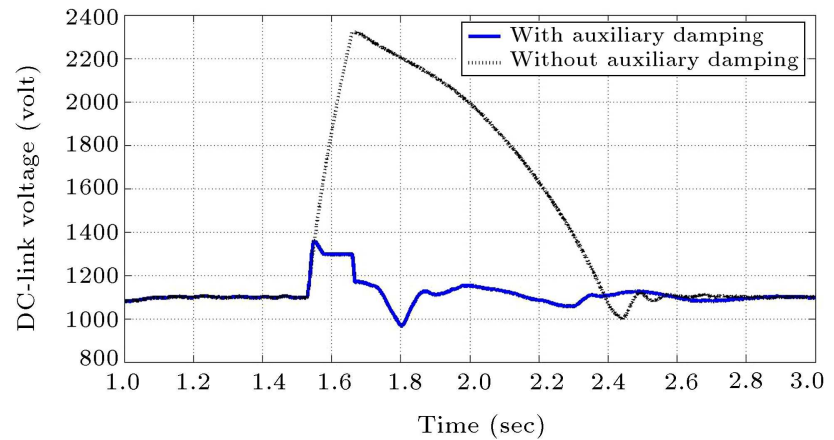

Figure 16. dc-link voltage with and without the auxiliary compensation signal under $70 \%$ grid voltage dip.

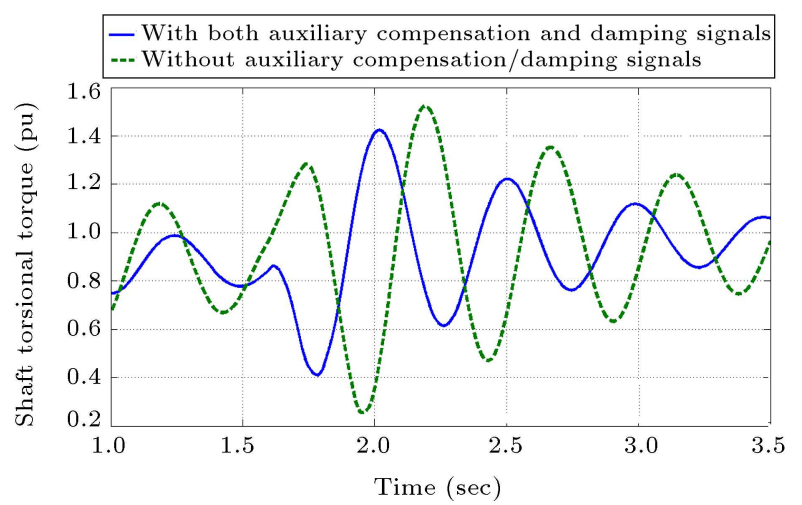

(a)

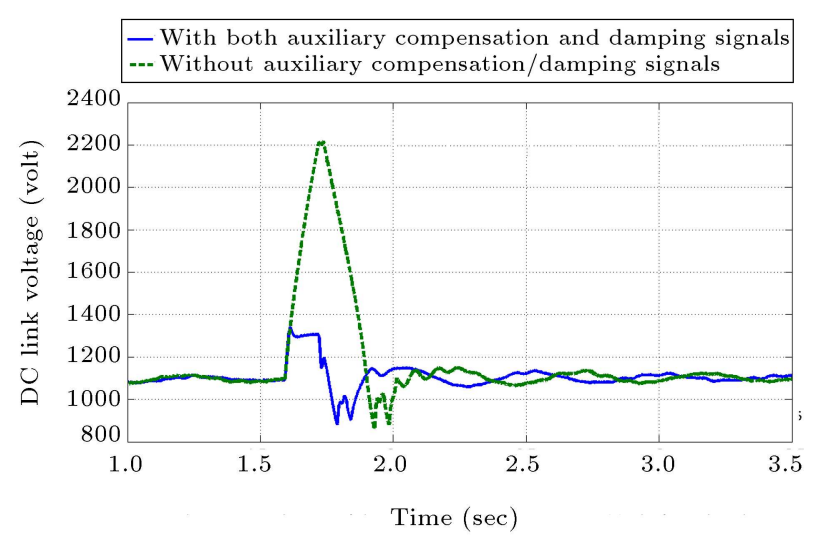

(b)

Figure 17. Time responses of the system under both wind speed variations and grid volatge dip, with and without the proposed compensation approaches: (a) Shaft torsional torque and (b) generator speed.

proposed compensation signal in Figure 10 limits the dc-link voltage below $1300 \mathrm{~V}$.

In the following, to limit the dc-link voltage below the threshold value, a dc-chopper with a dump resistor is employed in the dc-link part, as depicted in Figure 19. The threshold value of the dc-link voltage is considered to be 1.15 times the reference of the dc link voltage, i.e., $1.15 \times 1100=1210$ V. Figure 20 (a) shows the dc-link voltage in the case without the auxiliary 


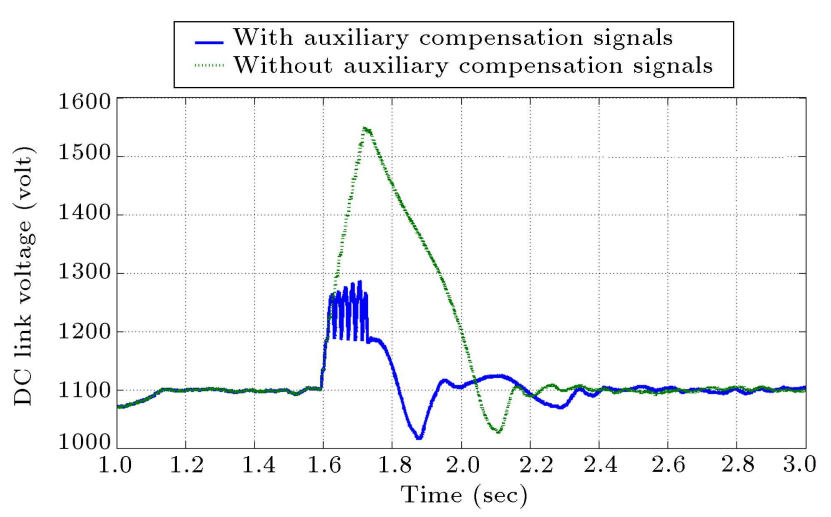

Figure 18. dc-link voltage with and without the auxiliary compensation signal under $70 \%$ single-phase voltage dip.

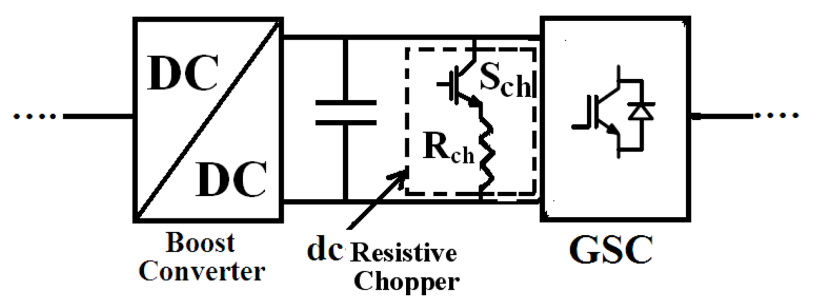

Figure 19. PMSG with dc-chopper protection.

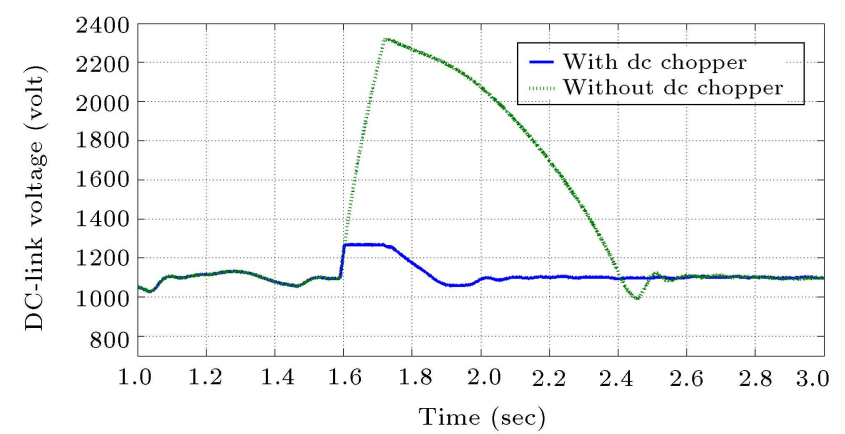

(a)

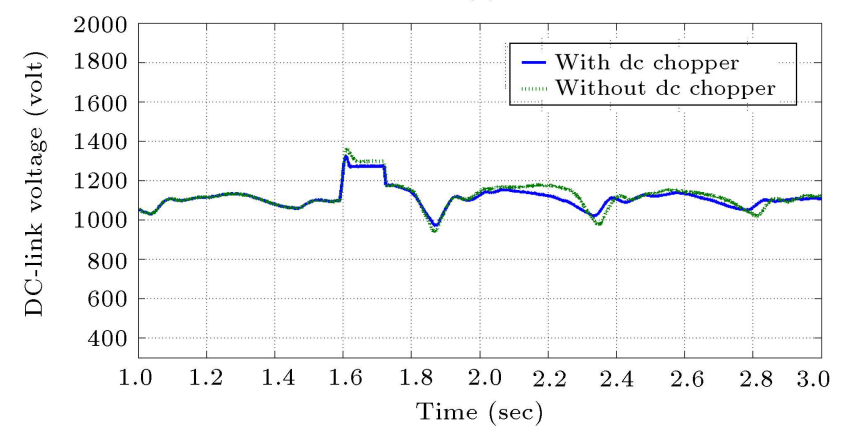

(b)

Figure 20. dc-link voltage with and without dc-chopper protection under $70 \%$ grid voltage dip: (a) Without the auxiliary compensation signal and (b) with the auxiliary compensation signal.

compensation signal, with and without the dc-chopper. It is clear that without the auxiliary compensation signal and dc chopper, the dc-link voltage during the fault reaches the high value of $2300 \mathrm{~V}$. In this case, by using the dc chopper, the dc link voltage is limited to

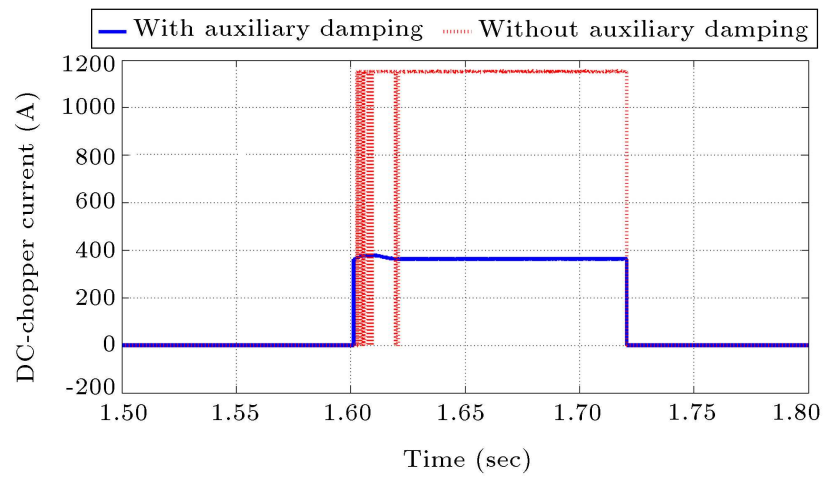

Figure 21. Dc chopper current with and without auxiliary damping.

$1265 \mathrm{~V}$ by dissipating energy on the chopper resistance. Also, Figure 20(b) shows the dc-link voltage in the case of the auxiliary compensation signal, with and without the dc-chopper. It is clear that in this case, the dc link voltage is limited to a large extent by the auxiliary damping signal and the dc chopper limits the dc link voltage slightly.

Also, Figure 21 shows the dc chopper current for the cases with and without the auxiliary compensation signal. According to Figure 21, in the case without the auxiliary compensation signal, the dc chopper current during the fault is $1175 \mathrm{~A}$, the dump resistor is $1.1 \Omega$, and $170.9 \mathrm{kj}$ energy is dissipated on the $\mathrm{dc}$ chopper resistance during the fault. On the other hand, in the case of the auxiliary compensation signal, the $\mathrm{dc}$ chopper current during the fault is $350 \mathrm{~A}$; the dump resistor is $3.5 \Omega$; and $55.4 \mathrm{kj}$ energy is dissipated on the dc chopper resistance during the fault. Hence, in the case of the auxiliary compensation signal, the energy dissipated on the dc chopper is much less than the one in the case without the auxiliary compensation signal. Therefore, by using the auxiliary compensation approach, the size of the dc chopper and the energy dissipated on the dump resistor are reduced significantly.

\section{Conclusion}

This paper enhanced the dynamic performance of the grid-connected PMSG-WT employing the boost converter-diode rectifier as the machine side converter. In this way, the boost converter control was modified in order to improve the damping of torsional oscillations and limit the dc link overvoltage in voltage dip conditions.

According to the obtained results, after the wind speed step change, torsional oscillations appeared in the responses of shaft torsional torque and generator speed, where in the case of the auxiliary damping signal, these oscillations were damped faster. It was shown that by using the auxiliary compensation signal, 
the change of the dc-link voltage due to voltage dip decreased considerably and thus, the LVRT capability of the Wind Turbine (WT) was enhanced significantly. Further, it was demonstrated that in the case of the auxiliary compensation signal, the energy dissipated on the dc chopper was much lower than the one in the case without the auxiliary compensation signal. Therefore, by modifying the boost converter control and adding the auxiliary control signals, the size of the dc chopper and the energy dissipated on the dump resistor were reduced significantly.

\section{Nomenclature}

PMSG Permanent Magnet Synchronous

WT Wind Turbine

MSC Machine Side Converter

$v_{s d q}, i_{s d q}$, dq-components of the stator voltage, current, and flux

$\psi_{s d q}$

$R_{s}, L_{s}, X_{s}$ PMSG stator resistance, synchronous inductance, and reactance

$\psi_{p m} \quad$ PMSG stator flux linkage due to rotor permanent magnet

$T_{e}, \omega_{r} \quad$ Generator torque and rotational speed

$V_{d} \quad$ Diode rectifier output voltage

$L_{b} \quad$ Boost converter inductance

$d \quad$ Duty cycle of the boost converter switch

$\omega_{i} \quad$ Closed loop bandwidth of the boost converter current

$T_{t}, \omega_{t} \quad$ Turbine torque and rotational speed

$H_{g}, H_{t} \quad$ Inertia constants related to turbine and generator

DFIG Doubly Fed Induction Generator

GSC Grid Side Converter

$E_{g} \quad$ Stator back-emf voltage

$i_{b} \quad$ Boost converter current

$P_{s} \quad$ PMSG output active power

$V_{d c} \quad$ GSC dc link voltage

$T_{s h} \quad$ Shaft torsional torque

\section{References}

1. Mauricio, J.M., Marano, A., Gómez-Expósito, A., et al. "Frequency regulation contribution through variable-speed wind energy conversion systems", IEEE Trans. Power Syst., 24(1), pp. 173-180 (2009).

2. Chowdhury, M.M., Haque, M.E., Das, D., et al. "Modeling, parameter measurement and sensorless speed estimation of IPM synchronous generator for direct drive variable speed wind turbine application", Int. Trans. Electr. Energ. Syst., 25(9), pp. 1814-1830 (2014).

3. Margaris, I.D. and Hatziargyriou, N.D. "Direct drive synchronous generator wind turbine models for power system studies", 7th Mediterranean Conf. \& Exhibition on Power Gen., Trans., Dist. and Energy Convers. (2010).

4. Béchir, B., Faouzi, B., and Gasmi, M. "Wind energy conversion system with full-scale power converter and squirrel cage induction generator", Int. Journal of Physical Sciences, 7(46), pp. 6093-6104 (2012).

5. Uehara, A., Pratap, A., Goya, T., et al. "A coordinated control method to smooth wind power fluctuations of a PMSG-based WECS", IEEE Trans. Energy Convers., 26(2), pp. 550-558 (2011).

6. Alaboudy, A.H.K., Daoud, A.A., Desouky, S.S., et al. "Converter controls and flicker study of PMSG-based grid connected wind turbines", Ain Shams Engineering Journal, 4(1), pp. 75-91 (2013).

7. Rajaei, A.H., Mohamadian, M., Dehghan, S.M., et al. "PMSG-based variable speed wind energy conversion system using Vienna rectifier", Eur. Trans. Electr. Power., 21(1), pp. 954-972 (2011).

8. Freire, N.M. and Cardoso, A.J.M. "Fault-tolerant PMSG drive with reduced DC-link ratings for wind turbine applications", IEEE Emerg. Sel. Top. power Electron., 2(1), pp. 26-34 (2014).

9. Zhang, S., Tseng, K.J., Vilathgamuwa, D.M., et al. "Design of a robust grid interface system for PMSGbased wind turbine generators", IEEE Trans. Ind. Electrons., 58(1), pp. 316-328 (2011).

10. Rahimi, M. "Mathematical modeling, dynamic response analysis and control of PMSG based wind turbines operating with an alternative control structure in power control mode", Int. Trans. Electr. Energ. Syst., 27(12), pp. 1-18 (2017).

11. Rahimi, M. "Modeling, control and stability analysis of grid connected PMSG based wind turbine assisted with diode rectifier and boost converter", Electrical Power and Energy Systems-Elsevier, 93, pp. 84-96 (2017).

12. Urtasun, A., Sanchis, P., San Martin, I., et al. "Modeling of small wind turbines based on PMSG with diode bridge for sensorless maximum power tracking", Renewable Energy, 55, pp. 138-149 (2013).

13. Aubrée, R., Auger, F., Macé, M., et al. "Design of an efficient small wind-energy conversion system with an adaptive sensorless MPPT strategy", Renewable Energy, 86, pp. 280-291 (2016). 
14. Şerban, I. and Marinescu, C. "A sensorless control method for variable-speed small wind turbines", Renewable Energy, 43, pp. 256-266 (2012).

15. Yu, K.N. and Liao, C.K. "Applying novel fractional order incremental conductance algorithm to design and study the maximum power tracking of small wind power systems", J. Applied Res. and Tech., 13(2), pp. 238-244 (2015).

16. Mozayan, S.M., Saad, M., Vahedi, H., et al. "Sliding mode control of PMSG wind turbine based on enhanced exponential reaching law", IEEE Trans. Ind. Elec., 63(10), pp. 6148-6159 (2016).

17. Yaramasu, V., Wu, B., Alepuz, S., et al. "Predictive control for low-voltage ride-through enhancement of three-level-boost and NPC-converter-based PMSG wind turbine", IEEE Trans Ind. Elec., 61(12), pp. 6832-6843 (2014).

18. Yaramasu, V. and $\mathrm{Wu}, \mathrm{B}$. "Predictive control of a three-level boost converter and an NPC Inverter for high-power PMSG-based medium voltage wind energy conversion systems", IEEE Trans. Power Elec., 29(10), pp. 5308-5322 (2014).

19. Nallusamy, S., Velayutham, D., and Govindarajan, U. "Design and implementation of a linear quadratic regulator controlled active power conditioner for effective source utilisation and voltage regulation in low-power wind energy conversion systems", IET Power Elec., 8(11), pp. 2145-2155 (2015).

20. Barote, L., Marinescu, C., and Cirstea, M.N. "Control structure for single-phase stand-alone wind-based energy sources", IEEE Trans. Ind. Elec., 60(2), pp. 764-772 (2013).

21. Mesbahi, A., Saad, A., Khafallah, M., et al. "Boost converter analysis to optimise variable speed PMSG Wind generation system", Int. Renew. and Sust. Energy Conf. (IRSEC), pp. 275-280 (2013).

22. Putri, R.I., Pujiantara, M., Priyadi, A., et al. "Maximum power extraction improvement using sensorless controller based on adaptive perturb and observe algorithm for PMSG wind turbine application", IET Electric Power Applications, 12(4), pp. 455-462 (2018).

23. Ackermann, T., Wind Power in Power Systems, 1st Ed., Wiley (2005).

24. Hansen, A.D. and Michalke, G. "Modeling and control of variable-speed multi-pole permanent magnet synchronous generator wind turbine", Wind Energy, 11(5), pp. 537-554 (2008).

25. Jia, F., Wang, R., Li, Z., et al. "Torsional vibration suppression of DFIG drive-chain under grid fault", Electr. Power Autom. Equip, 35, pp. 74-80 (2015).
26. Mohammadi, E., Fadaeinedjad, R., and Moschopoulos, G. "Implementation of internal model based control and individual pitch control to reduce fatigue loads and tower vibrations in wind turbines", J. Sound Vibr., 421, pp. 132-152 (2018).

27. Liu, L., Xie, D., Chu, H., et al. "Damping method for torsional vibrations in a DFIG wind turbine system based on small-signal analysis", Electr. Power Comp. Syst., 45(5), pp. 560-573 (2017).

28. White, W.N., Fateh, F., and Gruenbacher, D. "Impact of sliding mode bandwidth and disturbance estimation on damping of wind turbine torsional vibration", American Control Conf. (ACC), pp. 3182-3187 (2016).

29. Xi, X., Geng, H., Yang, G., et al. "Torsional oscillation damping control for DFIG-Based wind farm participating in power system frequency regulation", IEEE Trans. Indust. App., 54(4), pp. 3687-3701 (2018).

30. Liu, J., Zhou, F., Zhao, C., et al. "Mechanism analysis and suppression strategy research on permanent magnet synchronous generator wind turbine torsional vibration", ISA Trans., 92, pp. 118-133 (2019).

31. Derugo, P. and Szabat, K. "Damping of torsional vibrations of two-mass system using adaptive low computational cost fuzzy PID controller", 11th Int. Conf. on Power Elec. and Drive Systems, Sydney, Australia, pp. 1162-1165 (2015).

32. Li, Z., Tian, S., Zhang, Y., et al. "Active control of drive chain torsional vibration for DFIG-based wind turbine", Energies, 12(9), pp. 1-16 (2019).

33. Kina, A., Ludin, G.A., Senjyu, T., et al. "Torsional oscillation damping control for wind turbine generator under strong wind conditions", IEEE Region 10 Conf. (TENCON), Singapore, pp. 942-945 (2017).

34. Rahimi, M. and Beiki, A. "Efficient modification of the control system in PMSG based wind turbine for improvement of the wind turbine dynamic response and suppression of torsional oscillations", Int. Trans. Elect. Ener. Syst., 28(8), pp. 1-16 (2018).

35. Licari, J., Ugalde-Loo, C.E., Ekanayake, J.B., et al. "Comparison of the performance and stability of two torsional vibration dampers for variable-speed wind Turbines", Wind Energy, 18(9), pp. 1545-1559 (2015).

36. Beiki, A. and Rahimi, M. "An efficient sensorless approach for energy conversion enhancement and damping response improvement in PMSG based wind turbines", Int. Trans. Elect. Energy Syst., 29(1), pp. 1-18 (2019).

37. Mohan, N., Undeland, T.M., and Robbins, W.P., Power Electronics: Converters, Applications, and Design, Wiley, 2nd Ed. (1995).

38. Pietilainen, K., Harnefors, L., Petersson, A., et al. "DC-link stabilization and voltage sag ride-through of inverter drives", IEEE Trans. Ind. Elec., 53(4), pp. 1261-1268 (2006). 
Table A.1. System under study parameters.

\begin{tabular}{ccc}
\hline Component & Parameter & Value \\
\hline PMSG WT parameters & Rated power & $2 \mathrm{MW}$ \\
& Rated stator voltage & $690 \mathrm{~V}$ \\
& Rated frequency & $50 \mathrm{~Hz}$ \\
& Number of pole pairs & 4 \\
& $\psi_{p m}$ & $0.95 \mathrm{pu}$ \\
& $R_{s}$ & $0.0087 \mathrm{pu}$ \\
& $L_{s}=L_{d}=L_{q}$ & $0.14 \mathrm{pu}$ \\
& $H_{g}, H_{t}$ & $0.6 \mathrm{sec}, 4 \mathrm{sec}$ \\
& $D_{t g}$ & $1 \mathrm{pu}$ \\
& $k_{s}$ & $0.6 \mathrm{pu} / \mathrm{elec} . \mathrm{rad}$ \\
\hline WT tansformer parameters & $X_{t r a n s}$ & $0.1 \mathrm{pu}$ \\
\hline Boost converter parameters & $R_{b}, L_{b}$ & $5 \Omega, 2.5 \mathrm{mH}$ \\
\hline GSC parameters & Dc link voltage $V_{d c}$ & $1100 \mathrm{~V}$ \\
& Dc link capacitor $C_{d_{c}}$ & $50 \mathrm{mF}$ \\
& $\mathrm{GSC}$ output LC filter $L_{F}, C_{F}$ & $0.15 \mathrm{pu}, 0.07 \mathrm{pu}$ \\
\hline
\end{tabular}

\section{Appendix}

Parameters of the $2 \mathrm{MW}, 690 \mathrm{~V}, 50 \mathrm{~Hz}$, PMSG-WT are given in Table A.1.

\section{Biographies}

Amir Noori Khezrabad received his BSc degree in Electrical Power Engineering in 2014 from Shahid Beheshti University (SBU), Shahid Abbaspour School of Technology, Tehran, Iran. He obtained the MSc degree in Electrical Power Engineering from University of Kashan, Kashan, Iran in 2017. Currently, he is with Tehran Regional Electric Company (TREC). His current research interests include renewable energy systems and power system studies.

Mohsen Rahimi received his BSc degree in Electrical Engineering in 2001 from Isfahan University of Technology, Isfahan, Iran. He obtained both his $\mathrm{MSc}$ and PhD degrees in Electrical Engineering from Sharif University of Technology (SUT), Tehran, Iran in 2003 and 2011, respectively. He joined the Department of Electrical and Computer Engineering at University of Kashan, Kashan, Iran as an Assistant Professor in 2011. Currently, he is an Associate Professor at University of Kashan and his major research interests include modeling and control of renewable energy sources, wind turbines, and microgrids. 